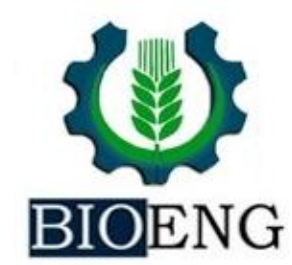

\title{
CULTIVO DA RÚCULA EM SISTEMA HIDROPÔNICO SOB DIFERENTES CONCENTRAÇÕES DE SAIS
}

\author{
C. M. S. Guardabaxo' ${ }^{1}$ K. C. C. Assis ${ }^{2 *}$, F. C. Figueiredo ${ }^{1}$, L. F. Silva ${ }^{2}$
}

1 Instituto Federal de Educação, Ciência e Tecnologia do Sul de Minas - IFSULDEMINAS, Muzambinho-MG, Brasil

${ }^{2}$ Faculdade de Ciências Agronômicas Universidade Estadual Paulista "Julio de Mesquita Filho" FCA/Unesp, Botucatu-SP, Brasil

Article history: Received 31 August 2020; Received in revised form 20 September 2020; Accepted 21 September 2020; Available online 30 September 2020.

\section{RESUMO}

Objetivou-se com o presente trabalho avaliar diferentes concentrações de sais na solução nutritiva proposta por Furlani (1999) em cultivo hidropônico de rúcula no sistema deep film techinique (DFT) em ambiente protegido. $\mathrm{O}$ delineamento utilizado foi inteiramente casualizado (DIC) com quatro repetições, sendo os tratamentos cinco concentrações de sais: 33\%, 67\%, 100\%, $133 \%$ e $167 \%$ em relação a concentração original com adaptação do nutriente cobre na concentração $0,064 \mathrm{mg} \mathrm{L}^{-1}$. As mudas foram conduzidas durante 30 dias em sistema hidropônico (DFT). Os resultados mostraram que o incremento de sais a partir da dose de $67 \%$ não apresentou ganhos significativos em massa seca. Os resultados também não apresentaram resultados significativos em teores foliares, que em concentrações altas apresentaram interação negativa entre alguns nutrientes. Para o acúmulo dos nutrientes nitrogênio, fosforo e potássio e composição centesimal nenhuma concentração de sais acima de $100 \%$ propiciou aumento efetivo que justificasse o aumento do custo inerente ao aumento dos sais na solução. O cultivo de rúcula apresenta melhor desenvolvimento com concentrações de sais entre 67 e $100 \%$.

Palavras-chave: Solução Nutriva. Floating. Eruca sativa. Brássica. Rendimento nutricional.

\section{RUCULA GROWING IN A HYDROPONIC SYSTEM UNDER DIFFERENT SALT CONCENTRATIONS}

\begin{abstract}
The aim of this study was to evaluate different concentrations of salts in the nutrient solution proposed by Furlani (1999) in hydroponic arugula cultivation in the deep film techinique (DFT) system in a protected environment. The design used was completely randomized (DIC) with four replications, with the treatments being five concentrations of salts: $33 \%, 67 \%, 100 \%, 133 \%$ and $167 \%$ in relation to the original concentration with adaptation of the nutrient copper in the concentration $0.064 \mathrm{mg} \mathrm{L}-1$. The seedlings were conducted for 30 days in a hydroponic system (DFT). The results showed that the increase of salts from the $67 \%$ dose did not show significant gains in dry mass. The results also did not show significant results in leaf contents, which in high concentrations showed a negative interaction between some nutrients. For the accumulation of nutrients nitrogen, phosphorus and potassium and chemical composition, no concentration of salts above $100 \%$ provided an effective increase that
\end{abstract}


justified the increase in the cost inherent to the increase in salts in the solution. Arugula cultivation shows better development with salt concentrations between 67 and 100\%.

Keywords: Nutritive Solution. Floating. Eruca sativa. Brassica. Nutritional yield

\section{INTRODUÇÃO}

Há uma crescente demanda por hortaliças com boa qualidade com oferta durante todo ano. Assim o investimento em novos sistemas de cultivos que adaptem as regiões ao cultivo tem sido intensificado (CARRIJO et al., 2004).

A rúcula (Eruca sativa) é uma brássica folhosa que é muito apreciada na forma de salada. Produzida em todas as regiões a partir do final da década de 1990, a rúcula vem conquistando maior espaço no mercado. A produção atual de rúcula não tem atendido à demanda dos grandes centros consumidores, fato este que está promovendo uma expansão desta cultura em diversas partes do Brasil, principalmente na região Sudeste (PURQUEIRO et al., 2007).

Segundo Trani et al. (1992), para o bom desenvolvimento da planta existe a necessidade de temperaturas entre 15 a $18{ }^{\circ} \mathrm{C}$, sendo que a melhor época de plantio ocorre durante o outono ou inverno. Apesar de se desenvolver melhor sob baixas temperaturas a rúcula tem sido cultivada em numerosas regiões durante diversas épocas do ano (FILGUEIRA, 2007).

Como alternativa às condições desfavoráveis para a cultura da rúcula, Furlani et al. (1999), destacam a adoção do cultivo protegido que permite ao produtor interferir nas condições ambientais e o uso do sistema hidropônico.

O cultivo hidropônico consiste em produção de plantas em meio líquido sem fixálas ao solo. O fato da planta não ter contato direto com o solo e ficar dentro de uma estufa, reduz bastante a contaminação e modifica as condições meteorológicas. Isto resulta em plantas mais sadias, podendo ser produzidas, praticamente, durante todo o ano. O sistema hidropônico vem aumentando gradativamente no Brasil devido à alta qualidade e produtividade obtida no cultivo além da diminuição de gastos inerentes a adubação e controle de pragas e doenças (SANTOS, 2000; ALBERONI, 1998).

Em uma comparação entre o cultivo no solo e a hidroponia, para a produção de alface, Santos (2000) obteve produção seis vezes maior no cultivo hidropônico em comparação ao cultivo no solo. Seus resultados foram de 52 toneladas por ano por hectare, para a produção no solo e 313 toneladas por ano por hectare na utilização do sistema hidropônico.

Um dos sistemas mais usuais para a hidroponia é denominado de floating conhecido também como deep film techinique (DFT). Neste sistema as plantas são mantidas sobre uma lâmina profunda (5 a $20 \mathrm{~cm}$ ), e tem suas raízes completamente submersas na solução nutritiva e suportadas por um sistema flutuante. A respiração das raízes ocorre através de um sistema de bombeamento de ar e a sustentação através de suporte físico (SANTOS et al., 2011).

No sistema hidropônico a solução nutritiva é o meio pelo qual os nutrientes previamente dissolvidos em água são colocados à disposição das plantas (ANDRIOLO, 1999). Para o sucesso do cultivo hidropônico é imprescindível conhecer os aspectos nutricionais e de manejo das plantas nesse sistema de produção. Aspectos como composição da solução nutritiva, vazão da solução e condições locais podem influenciar na produção (RODRIGUES, 2002).

Muitas formulações vêm sendo testadas para composição da solução nutritiva, no entanto resultados de Santos (2000) evidenciaram que não há grandes diferenças na produtividade entre as soluções nutritivas comumente utilizadas nas oleícolas. Guerra et al. (2004) testou diferentes concentrações da 
solução proposta por Furlani (1998) em rúcula no sistema NFT e não obteve resultados significativos nem quando as concentrações de sais foram reduzidas em $50 \%$. Considerando a crescente necessidade da diminuição das concentrações das soluções nutritivas seja por

\section{MATERIAL E MÉTODOS}

O experimento foi desenvolvido em casa de vegetação, no setor de Biotecnologia do Instituto Federal de Educação, Ciência e Tecnologia do Sul de Minas Gerais, Muzambinho-MG, em maio de 2018.

O município de Muzambinho, que pertence à região sul do estado de Minas Gerais, apresenta coordenadas geográficas de latitude: $21^{\circ} 20^{\prime} 59,94^{\prime}$ 'S e longitude: $46^{\circ} 31^{\prime}$ 34,82 " W, com média de 1013 metros de altitude.

O clima da região é temperado úmido com inverno seco e verão moderadamente quente (Cwa), segundo a classificação de Köppen (SÁ JUNIOR et al., 2012).

As mudas de rúcula cv. Astro. A foram conduzidas em sistema hidropônico Floating, em caixas com capacidade volumétrica de 36 litros equipadas com bomba para oxigenação. Os tratamentos consistiram em cinco concentrações de sais: 33\%, 67\%, 100\%, 133\% e $167 \%$ em relação a concentração original proposta por Furlani et al. (1999) (Tabela 1) fatores econômicos ou ambientais como também foi exposto por Siddiqui et al. (1998).

Neste contexto, o presente trabalho teve como objetivo avaliar diferentes concentrações de sais na solução nutritiva proposta por Furlani (1998) em cultivo hidropônico de rúcula no sistema (DFT) em ambiente protegido.

com adaptação do nutriente cobre na concentração $0,064 \mathrm{mg} \mathrm{L}^{-1}$ que foi trabalhado por Grangeiro et al. (2003) como o valor mais adequado para se obter maior produtividade em rúcula. $\mathrm{O}$ delineamento utilizado foi inteiramente casualizado (DIC) com quatro repetições sendo que cada repetição foi representada por caixa com 12 orifícios, sendo 15 plantas por orifício totalizando 180 plantas.

As mudas de rúcula foram obtidas em viveiro com certificação na cidade de São José do Rio Pardo - SP. Para suporte das mudas na caixa foi utilizada uma placa de isopor.As mudas passaram por um processo de adaptação antes de serem inseridas definitivamente nas caixas. Inicialmente todas ficaram na solução de $33 \%$ em um período de 24 horas. Posteriormente a esse processo as mudas dos demais tratamentos foram colocadas em solução $67 \%$ por 24 horas. O processo se repetiu até que as mudas do tratamento $167 \%$ chegasse a sua concentração.

Tabela 1. Formulação e fontes de nutrientes utilizada para solução nutritiva Furlani (1999) adaptada

\begin{tabular}{ccc}
\hline & Fertilizante & $\mathrm{g} / 10 \mathrm{~L}$ \\
\hline $\mathrm{A}$ & Nitrato de cálcio Hydros® Especial & 750 \\
\hline $\mathrm{B}$ & Nitrato de potássio & 500 \\
\cline { 2 - 3 } & Fosfato monoamônio & 150 \\
\cline { 2 - 3 } $\mathrm{C}$ & Sulfato de magnésio & 400 \\
\cline { 2 - 3 } & Sulfato de cobre & 0,27 \\
\cline { 2 - 3 } & Sulfato de zinco & 0,5 \\
\cline { 2 - 3 } & Sulfato de manganês & 1,5 \\
\cline { 2 - 3 } & Ácido bórico & 1,5 \\
\cline { 2 - 3 } & Molibdato de sódio ou & 6,15 \\
\hline
\end{tabular}

Fonte: (Adaptado Furlani 1999) 
As mudas de rúcula foram obtidas em viveiro com certificação na cidade de São José do Rio Pardo - SP. Para suporte das mudas na caixa foi utilizada uma placa de isopor. $\mathrm{Na}$ placa de isopor foram realizados doze orifícios circulares com diâmetro de $5 \mathrm{~cm}$ em duas fileiras iguais, cujo espaçamento entre linhas e plantas foi respectivamente de $20 \mathrm{~cm}$ e $8 \mathrm{~cm}$. Cada orifício acomodou 15 plantas. Para o manejo da solução nutritiva foi controlada a Condutividade Elétrica (CE) com o condutivímetro de bolso HI98318-Hanna Instruments ${ }^{\circledR}$ e o $\mathrm{pH}$ foi mantido na faixa de 5,5 a 6,5 com o pH de bolso HI 98107 (Tabela 2).

Tabela 2. Condutividade elétrica e pH das concentrações de sais trabalhadas na solução hidropônica no cultivo de rúcula.

\begin{tabular}{ccc}
\hline Tratamento & $\mathrm{pH}$ & $\mathrm{CE}(\mathrm{dS} / \mathrm{m})$ \\
\hline $33 \%$ & 6,40 & 0,70 \\
$67 \%$ & 6,47 & 1,54 \\
$100 \%$ & 6,55 & 2,32 \\
$133 \%$ & 6,37 & 2,69 \\
$167 \%$ & 6,47 & 3,52 \\
\hline
\end{tabular}

Fonte: Autores 2018

A reposição dos sais foi realizada quando a condutividade elétrica da solução apresentou redução de $20 \%$ do valor inicial.

A faixa de $\mathrm{pH}$ adotada foi determinada segundo trabalho realizado por Genúncio et al. (2006) que encontraram na mesma maiores desenvolvimentos da rúcula. A condutividade e o $\mathrm{pH}$ foram monitoradas diariamente, assim como também foi realizada a reposição dos sais na solução, sempre mantendo o volume inicial assegurando que o sistema radicular das plantas analisadas estivesse em contato com a solução o tempo todo.

A temperatura da casa de vegetação climatizada foi monitorada com auxílio termômetro digital de máxima e mínima (Figura 1).

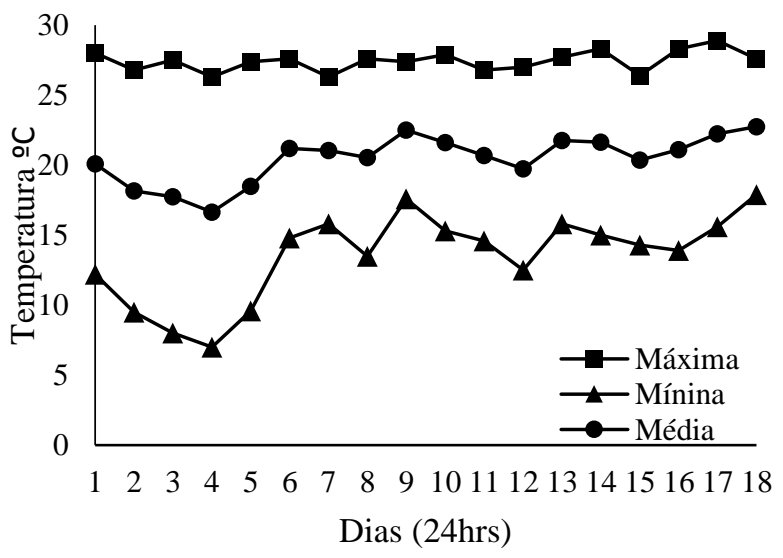

(Fonte: Autores 2018)

Figura 1. Temperatura no interior da casa de vegetação durante os dias de cultivo de rúcula hidropônica. IFSULDEMINAS - Muzambinho, 2018. 
As mudas foram conduzidas durante 19 dias em sistema hidropônico (DFT) e após esse período foram avaliados: biomassa seca parte aérea, biomassa seca sistema radicular, biomassa seca total e composição bromatológica. Os dados obtidos foram

\section{RESULTADOS E DISCUSSÃO}

Os resultados referentes a massa fresca e massa seca de parte aérea e sistema radicular são apresentados na Tabela 3.

As massas frescas de sistema radicular e parte aérea, bem como a relação entre as mesmas não diferiram entre os tratamentos preestabelecidos. Com relação ao sistema radicular a massa seca também não diferiu entre os tratamentos. A biomassa seca de parte aérea (BSPA), relação biomassa seca de parte aérea e raiz (BSPA/BSRA) e Biomassa seca total (BSTotal) diferiram entre as concentrações de sais adotadas para a rúcula.

O tratamento com $33 \%$ de sais proporcionou menor BSPA e BSTotal e diferiu submetidos à análise de variância e regressão no software estatístico SISVAR (FERREIRA, 2011), onde foi utilizado o teste $F$ para determinação das diferenças entre os tratamentos. significativamente de todos os demais tratamentos que não diferiram entre si. Tal resultado se deu devido à baixa concentração de nutrientes no tratamento, insuficiente para desenvolvimento da rúcula no máximo potencial produtivo.

Resultados semelhantes foram obtidos por Cometti et al., (2008) no cultivo hidropônico de alface, aonde foi encontrado massa seca $66 \%$ menor na concentração de $25 \%$ de sais de acordo com a formulação proposta por Furlani (1999), quando comparadas as médias de massa seca obtidas nas concentrações de $50 \%$ e $100 \%$ de sais que não apresentaram diferença estatística entre si.

Tabela 3. Biomassa fresca, seca e relação parte aérea e sistema radicular de rúcula cultivada sob diferentes concentrações de sais em sistema hidropônico DFT. (IFSULDEMINAS) Muzambinho- MG, 2018.

\begin{tabular}{ccccccccc}
\hline & & \multicolumn{3}{c}{ BSPA/ } & \multicolumn{3}{c}{ BFPA/ } \\
SAIS $(\%)$ & BSRA & BSPA & BSRA & BSTotal & BFRA & BFPA & BFRA & BFTotal \\
\hline 33 & $1,80 \mathrm{a}$ & $24,90 \mathrm{~b}$ & $13,70 \mathrm{c}$ & $26,72 \mathrm{~b}$ & $36,4 \mathrm{a}$ & $501,9 \mathrm{a}$ & $14,7 \mathrm{a}$ & $538,3^{\mathrm{a}}$ \\
67 & $2,02 \mathrm{a}$ & $32,32 \mathrm{a}$ & $16,01 \mathrm{~b}$ & $34,35 \mathrm{a}$ & $31,5 \mathrm{a}$ & $617,9 \mathrm{a}$ & $12,0 \mathrm{a}$ & $669,4^{\mathrm{a}}$ \\
100 & $2,00 \mathrm{a}$ & $36,95 \mathrm{a}$ & $18,54 \mathrm{a}$ & $38,95 \mathrm{a}$ & $39,4 \mathrm{a}$ & $655,8 \mathrm{a}$ & $16,0 \mathrm{a}$ & $695,2^{\mathrm{a}}$ \\
133 & $1,75 \mathrm{a}$ & $34,60 \mathrm{a}$ & $19,82 \mathrm{a}$ & $36,35 \mathrm{a}$ & $39,5 \mathrm{a}$ & $614,0 \mathrm{a}$ & $15,5 \mathrm{a}$ & $653,5^{\mathrm{a}}$ \\
167 & $1,87 \mathrm{a}$ & $37,77 \mathrm{a}$ & $20,14 \mathrm{a}$ & $39,65 \mathrm{a}$ & $37,6 \mathrm{a}$ & $640,1 \mathrm{a}$ & $17,9 \mathrm{a}$ & $677,7^{\mathrm{a}}$ \\
\hline CV $(\%)$ & 9,9 & 9,79 & 6,04 & 9,71 & 22,72 & 13,72 & 15,33 & 14,2 \\
\hline
\end{tabular}

As médias seguidas pela mesma letra na coluna não diferiram significativamente ao nível de $5 \%$ de probabilidade pelo teste Scott-Knott.

Para a variável (BSPA/BSRA) notou-se incremento significativo com o aumento das concentrações de sais. Os tratamentos na concentração de $33 \%$ de sais apresentaram a menor média para a variável e diferiu de todos os demais. As concentrações de 100, 133 e
$167 \%$ foram semelhantes e maiores que os demais tratamentos. As plantas tiveram maior desenvolvimento com o aumento da nutrição evidenciando que nenhuma concentração testada foi superior a demanda por nutrientes da rúcula. Tal resultado colabora para a hipótese 
defendida por Larigaurderie e Richards (1994), que afirma que as plantas adaptadas a condições de estresse alocam grande proporção de carboidratos para o aumento da fitomassa seca da raiz para buscar nutrientes de forma mais eficiente.

As análises bromatológicas estão apresentadas na Tabela 4. Para as variáveis fibra bruta e estrato etéreo não houve diferença. Para as variáveis proteína bruta, cinza, extrativos não nitrogenado e valor calórico pelo menos uma concentração de sal diferiu das demais.

A proteína bruta (Tabela 4) apresentou aumento significativo com o aumento da concentração de sais. $\mathrm{O}$ aumento da concentração de sais está correlacionado a formação de proteína pelas plantas. Resultados semelhantes foram encontradas por Viana et al. (2011) em forrageiras. $\mathrm{O}$ aumento do nitrogênio fornecido a elas promove ganhos significativos em proteína bruta.
Para a variável valor calórico, cinzas e extrativos não nitrogenados houve aumento significativo nas médias com o aumento da concentração de sais até a concentração de $100 \%$. Após dada concentração não houve diferença significativa ao nível de 0,05 de significância.

A partir das análises de todos as variáveis notou-se que o incremento de sais a partir da dose de 67\% não apresentou ganhos significativos em massa seca. Os resultados também não apresentaram resultados significativos em teores foliares, que em concentrações altas apresentaram interação negativa entre alguns nutrientes. Para o acúmulo dos nutrientes nitrogênio, fosforo e potássio e composição centesimal nenhuma concentração de sais acima de $100 \%$ propiciou aumento efetivo que justificasse o aumento do custo inerente ao aumento dos sais na solução.

A faixa ótima para o cultivo da rúcula determinada por Trani et al. (2014) foi atendida por todas as concentrações de sais testadas.

Tabela 4. Resultados Bromatológicos de massa seca de parte aérea de rúcula cultivada sob diferentes concentrações de sais em sistema hidropônico DFT. (IFSULDEMINAS) Muzambinho- MG, 2018. FB (fibra bruta), EE (extrato etéreo), PB (proteína bruta), Cinz (Cinzas), ENN (extrativos não nitrogenados).

\begin{tabular}{ccccccc}
\hline \multirow{2}{*}{ SAIS $(\%)$} & \multicolumn{5}{c}{ Análise Bromatológica } \\
\cline { 2 - 7 } & $\mathrm{FB}(\%)$ & $\mathrm{EE}(\%)$ & $\mathrm{PB}(\%)$ & $\mathrm{Cinz}(\%)$ & $\mathrm{ENN}(\%)$ & V.Calórico $(\mathrm{kcal} / 100 \mathrm{~g})$ \\
\hline 33 & $0,006 \mathrm{a}$ & $0,064 \mathrm{a}$ & $0,96 \mathrm{~d}$ & $1,05 \mathrm{~b}$ & $2,30 \mathrm{c}$ & $8,66 \mathrm{c}$ \\
67 & $0,007 \mathrm{a}$ & $0,070 \mathrm{a}$ & $1,12 \mathrm{c}$ & $1,06 \mathrm{~b}$ & $2,46 \mathrm{~b}$ & $9,37 \mathrm{~b}$ \\
100 & $0,006 \mathrm{a}$ & $0,081 \mathrm{a}$ & $1,21 \mathrm{~b}$ & $1,12 \mathrm{a}$ & $2,68 \mathrm{a}$ & $10,08 \mathrm{a}$ \\
133 & $0,007 \mathrm{a}$ & $0,068 \mathrm{a}$ & $1,26 \mathrm{~b}$ & $1,13 \mathrm{a}$ & $2,64 \mathrm{a}$ & $10,17 \mathrm{a}$ \\
167 & $0,005 \mathrm{a}$ & $0,062 \mathrm{a}$ & $1,35 \mathrm{a}$ & $1,13 \mathrm{a}$ & $2,57 \mathrm{a}$ & $10,49 \mathrm{a}$ \\
\hline $\mathrm{CV}(\%)$ & 9,9 & 18,02 & 5,1 & 3,24 & 3,73 & 3,63 \\
\hline
\end{tabular}

(*) As médias seguidas pela mesma letra na coluna não diferiram significativamente ao nível de 5\% pelo teste Scott-Knott.

Segundo Junior et al. (2007) sob o aspecto econômico, o melhor desempenho de uma solução com menor concentração total de nutrientes implica diretamente menor custo de produção, considerando que os sais fertilizantes utilizados na hidroponia são originados de matérias primas importadas e, por conseguinte, onerosas ao custo de produção, tendo em vista o caráter intensivo dessa forma de cultivo.

Neste caso as concentrações mais indicadas da formulação proposta por Furlani (1999) é a que contempla $100 \%$ e $67 \%$ dos sais. 


\section{CONCLUSÕES}

O cultivo de rúcula apresenta melhor desenvolvimento com concentrações de sais entre 67 e $100 \%$ da composição proposta por Furlani (1999).

\section{REFERÊNCIAS BIBLIOGRÁFICAS}

ALBERONI, R.B. Hidroponia como instalar e manejar o plantio de hortaliças dispensand o o uso do solo. São Paulo: Nobel, 1998. 102p.

ANDRIOLO, J. L. Fisiologia das culturas protegidas. Santa Maria: UFSM, 1999. 142p.

APARECIDO, L. E. O; SOUZA, P. S. Boletim Climático $\mathbf{n}^{\circ}$ 9- Janeiro a dezembro de 2013. Disponível em: http: <//www.muz.ifsuldeminas.edu.br/images/storie s/pdf/2014/boletim_clima_dezembro.pdf.> Acesso em: 07/07/2018.

CARRIJO, O. A.; VIDAL, M. C.; REIS, N. V. B. DOS; SOUZA, R. B. DE; MAKISHIMA, N. Produtividade do tomateiro em diferentes substratos e modelos de casas de vegetação. Horticultura Brasileira, v. 22, n. 1, p. 05-09, jan./mar. 2004.

CHEN, B. M; WANG, Z. H; LI, S. X; WANG, G. X; SONG, H. X; WANG, X. N. Effects of nitrate supply on plant growth, nitrate accumulation, metabolic nitrate concentration and nitrate reductase activity in three leafy vegetables. Plant Science v.167, p.635-643. 2004

COMETTI NN; MATIAS GCS; ZONTA E; MARY W; FERNANDES MS. Efeito da concentração da solução nutritiva no crescimento da alface em cultivo hidropônicosistema NFT. Horticultura Brasileira, v.26, p.252-257, 2008.

FERREIRA, D.F. Sisvar: um sistema computacional de análise estatística. Ciência e
$\mathrm{O}$ aumento do nitrogênio na solução nutritiva propicia aumento significativo no teor de proteínas na rúcula.

Agrotecnologia. v.35, n.6. Lavras. Nov./Dec.2011.

FILGUEIRA, F. A. R. Novo manual de olericultura: agrotecnologia moderna na produção e comercialização de hortaliças. 3. ed. Viçosa: Editora UFV, 2007. 293 p.

FURLANI, P.R; SILVEIRA, L.C.P; BOLONH EZI, D; FAQUIN, N. Cultivo hidropônico de plantas. Campinas: Instituto Agronômico, 1999, 52p.

GENUNCIO, G. C; OLIVEIRA, S. A. S; AHMED, C. R; MARTINS, A. S; MAJEROWICZ, N. Cultivo Hidropônico de Rúcula (Euruca sativa) em diferentes níveis de pH. In: 46 congresso brasileiro de olericultura, 2006, Goiania. Horticultura Brasileira, 2006. v. 24. p. 203-204.

GRANGEIRO, L. C.; COSTA, C. C.; CECÍlIO FILHO, A. B. ; GRILLI, G. V. G. ; COELHO, R. L. ; BERGAMIN, L. G. . Produção de rúcula em hidroponia com diferentes concentrações de cobre. Horticultura Brasileira, Brasília, v. 21, n.1, p. 69-72, 2003

GUERRA, G. M. P; LUZ, J. M. Q ; HABER, L. L; SILVA, M. A. D. Cultivo hidropônico de rúcula em diferentes concentrações de solução nutritiva, em sistema NFT. In: 44 Congresso Brasileiro de Olericultura, 2004, Campo Grande-MS. Horticultura Brasileira Suplemento CD-ROM. Campo Grande-MS: UNIDERP, 2004. v. 22. p. 1-6. 
LUZ, Q. M. J; OLIVEIRA, C. R; AGUILAR, S. A; SANTOS, N. T. Cultivo de Artemisia absinthium L. sob concentrações de solução nutritiva em hidroponia. Revista Agrogeoambiental, Pouso Alegre, v. 10, n. 1, mar. 2018.

LARIGAUDERIE, A; RICHARDS, J.H. Root proliferation characteristics of seven perennial arid-land grasses in nutriente-enriched microsites. Oecologia, v.99, p.102-111, 1994.

LONERAGAN, J. F.; WEBB, M. J. Interactions between zinc and other nutrients affecting the growth of plants. In: ROBSON, A. D. (Ed.). Zinc in soil and plants. Dordrecht : Kluwer Academic,. p. 119-134, 1993.

MALAVOLTA, E; VITTI G. C; OLIVEIRA, S. A. Avaliação do estado nutricional das plantas, princípios e aplicações. Piracicaba: Potafós. 319p, 1997.

PAULUS, D.; DOURADO NETO, D.; FRIZZONE, J. A.; SOARES, T. M. Produção e indicadores fisiológicos de alface sob hidroponia com água salina. Horticultura Brasileira, v.28, n.1, p.29-35, 2010.

PÔRTO, M. L.A; ALVES, J. C; SOUZA, A. P; ARAÚJO, R. C; ARRUDA, J. A; TOMPSON JÚNIOR, U. A. Doses de nitrogênio no acúmulo de nitrato e na produção da alface em hidroponia. Horticultura Brasileira, v. 30, n. 3, 2012.

PURQUEIRO, L. F. V. Crescimento, produção e qualidade de rúcula (Eruca sativa Miller) em função do nitrogênio e da densidade de plantio. 2005. Tese (Doutorado em Agronomia-Horticultura) - Universidade Estadual Paulista, Botucatu.

RODRIGUES, L. R. F. Técnicas de cultivo hidropônico e de controle ambiental no manejo de pragas, doenças e nutrição vegetal em ambiente protegido. Jaboticabal: Funep/Unesp, 2002. 762 p.

SÁ JÚNIOR, A; CARVALHO, L.G; SILVA F.F. ALVES, M.C. Application of the Köppen classification for climatic zoning in the state of Minas Gerais, Brazil. Theor Appl Climatol v.108 p.1-7, 2012.

SANTOS, O. S. Hidroponia da alface. Centro de Ciências Rurais da Universidade de Santa Maria, Santa Maria, Rio Grande do Sul, 2000.

SANTOS, J. M; PEGORARO, R. I E; PEREIRA, P. R. G; FAGUNDES, J. L; MISTURA, C; AGOSTINI, M. A. V; MARTINEZ, H. E. P; FONTES, P. C. R. Comportamento da cebolinha cultivada sob diferentes níveis de cloreto de potássio em solução nutritiva. Revista Ceres, v.52, n.303, p. 729-738, 2005.

SANTOS, A. N. ; SILVA, E. F. F. ; SOARES, Tales Miler; DANTAS, R. M. L. ; SILVA, M.M. . Produção de alface em NFT e Floating aproveitando água salobra e o rejeito da dessalinização. Revista Ciência Agronômica (UFC. Impresso), v.42, p. 319-326, 2011.

SIDDIQI, M. V; KRONZUCKER, H. J; BRITTO, D. T; GLASS, D. M. Growth of a tomato crop at reduced nutrient concentrations as a strategy to limit eutrophication. J. Plant Nutrition v.21, p.1879-1895, 1998.

TRANI, P. E.; FORNASIER, J. B.; LISBÃO, R. S. Cultura da rúcula. Campinas: IAC. 1992. 8p. (Boletim técnico 146).

TRANI, E. P; PURQUÉRIO, V. F. L; FIGUEIREDO, B. J. G; TIVELLI, W. S; BLAT, F. S. Calagem e adubação da alface, almeirão, agrião d'água, chicória, coentro, espinafre e rúcula. Boletim Técnico IAC, n.97, 2. a ed. rev. atual, 16 p, 2014. 
VIANA, M. C. M; FREIRE, F. M; FERREIRA, J. J; MACÊDO, G. A. R; CANTARUTTI, R. B; MASCARENHAS, M. H. T. Adubação nitrogenada na produção e composição química do capim braquiária sob pastejo rotacionado. Revista Brasileira de Zootecnia, v.40, n.7, p.1497-1503, 2011. 